\title{
Nut consumption and incidence of metabolic syndrome after 6-year follow-up: the SUN (Seguimiento Universidad de Navarra, University of Navarra Follow-up) cohort
}

\author{
Alejandro Fernández-Montero, Maira Bes-Rastrollo, Juan J Beunza, \\ Maria Teresa Barrio-Lopez, Carmen de la Fuente-Arrillaga, Laura Moreno-Galarraga \\ and Miguel Angel Martínez-González* \\ Department of Preventive Medicine and Public Health, University of Navarra, C/Irrunlarrea 1, \\ 31008 Pamplona, Navarra, Spain
}

Submitted 19 May 2012: Final revision received 15 August 2012: Accepted 24 August 2012: First published online 23 0ctober 2012

\begin{abstract}
Objective: To assess the long-term relationship between tree nut consumption and the risk of developing metabolic syndrome (MetS).

Design: Nut consumption was collected using a validated 136-item FFQ. The MetS was defined according to the International Diabetes Federation and American Heart Association/National Heart, Lung, and Blood Institute harmonizing definition. The association between nut consumption and MetS was assessed with logistic regression models adjusting for potential confounders. We compared the incidence of MetS between extreme categories of nut intake ( $\geq 2$ servings/week $v$. never/almost never) after 6 years of follow-up.

Setting: The SUN Project (Seguimiento Universidad de Navarra, University of Navarra Follow-up) is a prospective cohort study, formed of Spanish university graduates. Information is gathered by mailed questionnaires collected biennially. Nut consumption and MetS information was collected by self-reported data. Subjects: Participants ( $n$ 9887) initially free of MetS or diabetes and followed up for a minimum of 6 years were included.

Results: We observed 567 new cases of MetS during follow-up. Participants who consumed nuts $\geq 2$ servings/week presented a $32 \%$ lower risk of developing MetS than those who never/almost never consumed (adjusted OR $=0 \cdot 68,95 \% \mathrm{CI}$ $0 \cdot 50,0 \cdot 92)$. The inverse association was stronger among participants who were health professionals.

Conclusions: Nut consumption was significantly associated with lower risk of developing MetS after a 6-year follow-up period in a cohort of Spanish graduates.
\end{abstract}

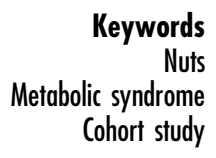

The Mediterranean food pattern has acquired an emerging role in cardiovascular epidemiology ${ }^{(1-3)}$. Nuts are included in the operational definition of the Mediterranean food pattern and the American Heart Association has recommended nut consumption since $2000^{(4)}$ because of reported beneficial effects of nuts on serum lipid and lipoprotein profiles, $\mathrm{CVD}^{(5,6)}$, type 2 diabetes mellitus ${ }^{(7)}$ and weight gain ${ }^{(8,9)}$. Specifically, a randomized trial supported the benefit of nut consumption on glycaemic control and lipid profile in type 2 diabetes ${ }^{(10)}$. Different nutritional compounds of nuts are thought to be responsible for this protection ${ }^{(6,7)}$. However, it is important to assess the specific role of long-term nut consumption on the risk of metabolic syndrome (MetS). This is relevant because MetS increases the risk of type 2 diabetes mellitus, CVD and total mortality ${ }^{(11)}$. Many reports have assessed the incidence of MetS in relation to dietary factors, but few of them have specifically analysed whether nut intake is associated in the long term with the future development of MetS. A cross-sectional study reported an independent inverse association between nut consumption and waist circumference $^{(12)}$, but prospective long-term studies are scarce. Importantly, in the first 1224 participants of the PREDIMED randomized trial, a Mediterranean diet enriched with tree nuts exerted a beneficial effect on the risk of developing MetS after 1 year of intervention ${ }^{(13)}$. However, the results beyond 1 year are not available and that trial only included elderly participants at high cardiovascular risk. The long-term potential effects of nut consumption on the incidence of the MetS, and the effects among healthy and younger adults, are largely unknown.

Our aim was to assess the association between nut consumption and the long-term risk of developing MetS in a cohort of healthy middle-aged adults. 


\section{Methods}

\section{Study population}

The SUN Project (Seguimiento Universidad de Navarra, University of Navarra Follow-up) is a prospective cohort study, formed of Spanish university graduates. The objectives, design and methods of the SUN cohort have been previously published ${ }^{(14-16)}$.

All participants had obtained a university degree and half of the participants are health professionals themselves. The cohort began in December 1999 and it is permanently open, with a dynamic design. Information is gathered by mailed questionnaires collected biennially. Because all participants included in the SUN cohort have university studies, a better control of confounding by education-related variables is achieved (i.e. the restriction procedure to control confounding is applied) which makes the interpretation of results easier and adds validity to the high-quality information derived from their questionnaires $^{(17)}$. In addition, several validation studies of the self-reported data by participants of the SUN Project have been published, including anthropometric data ${ }^{(18)}$, physical activity questionnaires ${ }^{(19)}$, the diagnosis of hypertension $^{(20)}$ and the specific diagnostic criteria data used for MetS definition ${ }^{(21,22)}$.

We conducted the present analyses in January 2012. To allow for 6-year follow-up, we considered as eligible all SUN participants who had responded to the baseline questionnaire before March 2004 and were free of MetS or diabetes at baseline ( $n$ 14247). We excluded 1445 participants who had extremely low or high total energy intake $(<3347 \mathrm{~kJ} / \mathrm{d}(<800 \mathrm{kcal} / \mathrm{d})$ or $>16736 \mathrm{~kJ} / \mathrm{d}(>4000 \mathrm{kcal} / \mathrm{d})$ for men; $<2092 \mathrm{~kJ} / \mathrm{d}(<500 \mathrm{kcal} / \mathrm{d})$ or $>14644 \mathrm{~kJ} / \mathrm{d}$
(>3500 kcal/d) for women) and 696 participants who had not answered any of the follow-up questionnaires (retention rate $=94 \cdot 6 \%$ ). Also, 2219 participants were excluded because they had missing information about components of the MetS registered on the 6-year follow-up questionnaire. No meaningful differences between these 2219 individuals and those retained were found. After these exclusions, 9887 participants entered the final analyses (Fig. 1).

The study was conducted according to the guidelines laid down in the Declaration of Helsinki and all procedures involving human subjects were approved by the institutional review board of the University of Navarra. Informed consent was implied once the baseline questionnaire was filled in.

\section{Assessment of dietary exposure and nuts consumption}

We used a 136-item semi-quantitative FFQ that has been previously validated in Spain ${ }^{(23,24)}$. Specific questions on nut consumption included walnuts, almonds, hazelnuts and peanuts. Also a dietitian was in charge of updating the nutrient databank by using the most up-to-date food composition tables from Spain ${ }^{(25,26)}$.

\section{Assessment of components of the metabolic syndrome}

MetS was defined according to the International Diabetes Federation and American Heart Association/National Heart, Lung, and Blood Institute harmonizing definition ${ }^{(27)}$, which requires the presence of at least three of the following five components: (i) elevated waist circumference according to the population- and country-specific definition ( $\geq 94 \mathrm{~cm}$ for men and $\geq 80 \mathrm{~cm}$ for women in Europids); (ii) elevated

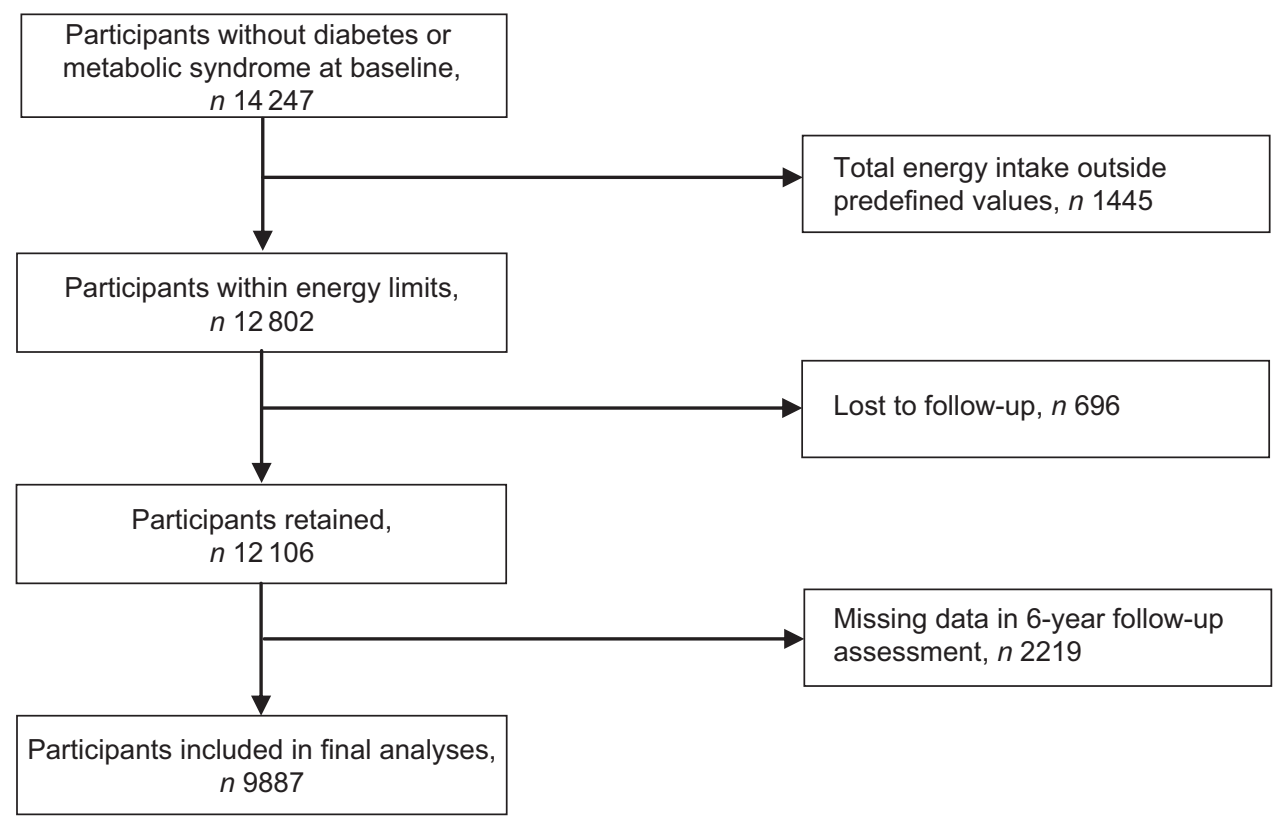

Fig. 1 Flowchart of participants in the present study 
TAG $(\geq 150 \mathrm{mg} / \mathrm{dl})$ or presence of drug treatment for elevated TAG; (iii) reduced HDL-cholesterol $(<40 \mathrm{mg} / \mathrm{dl}$ in males and $<50 \mathrm{mg} / \mathrm{dl}$ in females) or presence of drug treatment for reduced HDL-cholesterol; (iv) elevated blood pressure (systolic $\geq 130 \mathrm{mmHg}$ and/or diastolic $\geq 85 \mathrm{mmHg}$ ) or presence of antihypertensive drug treatment in a patient with history of hypertension; and (v) elevated fasting glucose $\geq 100 \mathrm{mg} / \mathrm{dl}$ or drug treatment for elevated glucose.

In the questionnaire used for the 6-year follow-up, validated $^{(21,22)}$ self-reported data about these specific MetS criteria were collected. Waist circumference was measured as established in a horizontal plane, midway between the inferior margin of the ribs and the superior border of the iliac crest. A measuring tape was sent via ordinary mail to all participants with the 6-year follow-up questionnaires, including an explanation of how to measure their own waist. The validation of the self-reported data about MetS was assessed in a specific sub-study with 287 participants from the SUN Project. Significant intra-class correlation coefficients between self-reported MetS components and their direct assessments by an experienced physician were obtained ${ }^{(21)}$. These results are freely accessible at http://www.unav.es/departamento/ preventiva/infoinvsun.

The validity of self-reported data on height (in centimetres) and body weight (in kilograms) has been also published in a specific report ${ }^{(10,18)}$.

\section{Potential confounding factors}

We adjusted the analyses for potential confounding characteristics including age, smoking, physical activity, alcohol consumption and total energy intake. Additionally, we also adjusted for baseline BMI.

\section{Statistical analysis}

According to the observed nut consumption frequency at baseline, nut intake was grouped into four categories: 'never/almost never', 'one to three times per month', 'once a week' or 'at least two times per week'. For stratified analyses we merged the two upper categories. Non-conditional logistic regression models were fit to assess the relationship between the frequency of nut consumption using these categories and the 6-year incidence of MetS. The lowest consumption was used as the reference category (those who never or almost never consumed nuts). Age-adjusted odds ratios and multivariate-adjusted odds ratios were estimated adjusting for the previously described confounding factors. Tests for trend were calculated assigning the median consumption ( $\mathrm{g} / \mathrm{d})$ of each category to all participants in that category and introducing this variable as continuous in the multivariable-adjusted logistic models. Effect modification by sex and health professional status was assessed using the likelihood ratio test for the product-term $(\mathrm{df}=1$, because we introduced in the product-terms the variable for nut consumption as a continuous variable as we did to test the linear trend). We also used as outcome every single component of the MetS and estimated adjusted odds ratios for that component for each of the three upper categories of nut consumption, always with the lowest category as the reference. All $P$ values used are two-tailed and $P<0.05$ was considered as statistically significant.

\section{Results}

Table 1 shows the baseline characteristics of participants according to their nut consumption. Older participants tended to have higher nut consumption. No significant differences in baseline BMI or time spent watching television were observed. Nut consumption was positively associated with physical activity, alcohol consumption and former smoking.

During the 6-year follow-up period, 567 cases of MetS were newly identified. In age-adjusted models, participants who consumed nuts $\geq 2$ servings/week presented a $34 \%$

Table 1 Baseline characteristics of participants according to nut consumption. The SUN Project (Seguimiento Universidad de Navarra, University of Navarra Follow-up), Navarra, Spain, 1999-2011

\begin{tabular}{|c|c|c|c|c|c|c|c|c|}
\hline & \multicolumn{8}{|c|}{ Nut consumption (servings) } \\
\hline & \multicolumn{2}{|c|}{ Never/almost never } & \multicolumn{2}{|c|}{ 1-3/month } & \multicolumn{2}{|c|}{ 1/week } & \multicolumn{2}{|c|}{$\geq 2 /$ week } \\
\hline & Mean & SD & Mean & SD & Mean & SD & Mean & SD \\
\hline$n$ & \multicolumn{2}{|c|}{2215} & \multicolumn{2}{|c|}{4394} & \multicolumn{2}{|c|}{1981} & \multicolumn{2}{|c|}{1297} \\
\hline Age (years) & 37 & $11 \cdot 9$ & 37 & $11 \cdot 1$ & 38 & $11 \cdot 4$ & 41 & $12 \cdot 1$ \\
\hline Women (\%) & \multicolumn{2}{|c|}{$67 \cdot 5$} & \multicolumn{2}{|c|}{$62 \cdot 3$} & \multicolumn{2}{|c|}{$55 \cdot 6$} & \multicolumn{2}{|c|}{$52 \cdot 1$} \\
\hline BMI $\left(\mathrm{kg} / \mathrm{m}^{2}\right)$ & $22 \cdot 9$ & $2 \cdot 9$ & $23 \cdot 0$ & $2 \cdot 8$ & $23 \cdot 1$ & $2 \cdot 8$ & $23 \cdot 0$ & $2 \cdot 8$ \\
\hline Alcohol consumption (g/d) & $5 \cdot 9$ & $9 \cdot 9$ & $6 \cdot 1$ & $8 \cdot 9$ & $7 \cdot 0$ & $9 \cdot 6$ & $7 \cdot 9$ & $10 \cdot 8$ \\
\hline Baseline weight $(\mathrm{kg})$ & $64 \cdot 7$ & $11 \cdot 8$ & $65 \cdot 4$ & $11 \cdot 8$ & $66 \cdot 6$ & $12 \cdot 1$ & $66 \cdot 0$ & $12 \cdot 0$ \\
\hline Television watching $(\mathrm{h} / \mathrm{d})$ & $1 \cdot 5$ & $1 \cdot 5$ & $1 \cdot 5$ & $1 \cdot 5$ & $1 \cdot 3$ & $1 \cdot 4$ & $1 \cdot 4$ & $1 \cdot 4$ \\
\hline Leisure-time physical activity (MET-h/week) & $19 \cdot 2$ & $21 \cdot 3$ & $19 \cdot 8$ & $21 \cdot 6$ & $21 \cdot 7$ & $21 \cdot 8$ & $24 \cdot 9$ & $27 \cdot 3$ \\
\hline Current smokers (\%) & \multicolumn{2}{|c|}{$23 \cdot 9$} & \multicolumn{2}{|c|}{$23 \cdot 2$} & \multicolumn{2}{|c|}{$23 \cdot 4$} & \multicolumn{2}{|c|}{$19 \cdot 0$} \\
\hline Former smokers (\%) & \multicolumn{2}{|c|}{$27 \cdot 9$} & \multicolumn{2}{|c|}{$27 \cdot 3$} & \multicolumn{2}{|c|}{$26 \cdot 9$} & \multicolumn{2}{|c|}{$33 \cdot 0$} \\
\hline Snacking between meals (\%) & \multicolumn{2}{|c|}{$30 \cdot 9$} & \multicolumn{2}{|c|}{$33 \cdot 1$} & \multicolumn{2}{|c|}{$36 \cdot 3$} & \multicolumn{2}{|c|}{$33 \cdot 5$} \\
\hline
\end{tabular}

MET, metabolic equivalent of task. 
Table 2 Incidence of metabolic syndrome (MetS) at 6-year follow-up according to baseline nut consumption, in the total sample and separating by sex. The SUN Project (Seguimiento Universidad de Navarra, University of Navarra Follow-up), Navarra, Spain, 1999-2011

\begin{tabular}{|c|c|c|c|c|c|c|c|c|c|}
\hline & \multicolumn{8}{|c|}{ Nut consumption (servings) } & \multirow[b]{3}{*}{$P$ for trend } \\
\hline & \multicolumn{2}{|c|}{ Never/almost never } & \multicolumn{2}{|c|}{$1-3 /$ month } & \multicolumn{2}{|c|}{$1 /$ week } & \multicolumn{2}{|c|}{$\geq 2 /$ week } & \\
\hline & OR & $95 \% \mathrm{Cl}$ & OR & $95 \% \mathrm{Cl}$ & OR & $95 \% \mathrm{Cl}$ & OR & $95 \% \mathrm{Cl}$ & \\
\hline \multicolumn{10}{|l|}{ Total sample } \\
\hline $\begin{array}{l}n \\
\text { MetS incidence (unadjusted) (\%) }\end{array}$ & \multicolumn{2}{|c|}{$\begin{array}{l}2215 \\
6 \cdot 6\end{array}$} & \multicolumn{2}{|c|}{$\begin{array}{c}4394 \\
4 \cdot 9\end{array}$} & \multicolumn{2}{|c|}{$\begin{array}{c}1981 \\
5 \cdot 9\end{array}$} & \multicolumn{2}{|c|}{$\begin{array}{c}1297 \\
6 \cdot 8\end{array}$} & \\
\hline Age- and sex-adjusted OR & $1 \cdot 00$ & Ref. & $0 \cdot 71$ & $0.57,0.90$ & 0.77 & $0.59,1.01$ & 0.66 & $0.49,0.89$ & 0.042 \\
\hline Multivariable adjusted* OR & 1.00 & Ref. & $0 \cdot 72$ & $0.57,0.91$ & 0.78 & $0.59,1.03$ & 0.68 & $0.50,0.92$ & 0.075 \\
\hline Additionally adjustedt OR & $1 \cdot 00$ & Ref. & $0 \cdot 72$ & $0.56,0.91$ & 0.79 & $0 \cdot 60,1 \cdot 04$ & $0 \cdot 73$ & $0.54,0.99$ & $0 \cdot 23$ \\
\hline \multicolumn{10}{|l|}{ Men } \\
\hline $\begin{array}{l}n \\
\text { MetS incidence (unadjusted) (\%) }\end{array}$ & \multicolumn{2}{|c|}{$\begin{array}{c}721 \\
12 \cdot 3\end{array}$} & \multicolumn{2}{|c|}{$\begin{array}{c}1655 \\
8 \cdot 9\end{array}$} & \multicolumn{2}{|c|}{$\begin{array}{l}880 \\
10 \cdot 0\end{array}$} & \multicolumn{2}{|c|}{$\begin{array}{c}621 \\
12 \cdot 2\end{array}$} & \\
\hline Age-adjusted OR & $1 \cdot 00$ & Ref. & $0 \cdot 77$ & $0.57,1.03$ & 0.86 & $0 \cdot 62,1 \cdot 19$ & 0.86 & $0.61,1 \cdot 22$ & 0.89 \\
\hline Multivariable-adjusted* OR & $1 \cdot 00$ & Ref. & 0.79 & $0.58,1.06$ & 0.88 & $0.63,1.23$ & 0.90 & $0.63,1.29$ & 0.91 \\
\hline Additionally adjustedt OR & $1 \cdot 00$ & Ref. & $0 \cdot 79$ & $0.58,1.07$ & $0 \cdot 88$ & $0 \cdot 63,1 \cdot 24$ & 0.97 & $0 \cdot 67,1 \cdot 39$ & 0.58 \\
\hline \multicolumn{10}{|l|}{ Women } \\
\hline$n$ & \multirow{2}{*}{\multicolumn{2}{|c|}{$\begin{array}{c}1494 \\
3.9\end{array}$}} & \multirow{2}{*}{\multicolumn{2}{|c|}{$\begin{array}{c}2739 \\
2 \cdot 5\end{array}$}} & \multirow{2}{*}{\multicolumn{2}{|c|}{$\begin{array}{c}1101 \\
2 \cdot 6\end{array}$}} & \multirow{2}{*}{\multicolumn{2}{|c|}{$\begin{array}{l}676 \\
1 \cdot 8\end{array}$}} & \\
\hline MetS incidence (unadjusted) (\%) & & & & & & & & & \\
\hline Age-adjusted OR & $1 \cdot 00$ & Ref. & $0 \cdot 64$ & $0.44,0.92$ & $0 \cdot 62$ & $0.39,0.99$ & $0 \cdot 29$ & $0 \cdot 15,0.56$ & $<0.001$ \\
\hline Multivariable-adjusted ${ }^{\star}$ OR & 1.00 & Ref. & $0 \cdot 64$ & $0.44,0.93$ & 0.62 & $0.38,1 \cdot 00$ & 0.29 & $0.15,0.56$ & $<0.001$ \\
\hline Additionally adjustedt OR & 1.00 & Ref. & $0 \cdot 62$ & $0.43,0.91$ & 0.66 & $0.40,1.08$ & 0.31 & $0 \cdot 16,0 \cdot 61$ & 0.001 \\
\hline
\end{tabular}

Ref., referent category.

*Adjusted for age, smoking, physical activity, alcohol consumption and total energy intake.

tAlso adjusted for BMI. 
Table 3 Incidence of metabolic syndrome (MetS) at 6-year follow-up according to baseline nut consumption, separating by health professional status. The SUN Project (Seguimiento Universidad de Navarra, University of Navarra Follow-up), Navarra, Spain, 1999-2011

\begin{tabular}{|c|c|c|c|c|c|c|c|}
\hline & \multicolumn{6}{|c|}{ Nut consumption (servings) } & \multirow[b]{3}{*}{$P$ for trenc } \\
\hline & \multicolumn{2}{|c|}{ Never/almost never } & \multicolumn{2}{|c|}{$1-3 /$ month } & \multicolumn{2}{|c|}{$\geq 1 /$ week } & \\
\hline & OR & $95 \% \mathrm{Cl}$ & OR & $95 \% \mathrm{Cl}$ & OR & $95 \% \mathrm{Cl}$ & \\
\hline \multicolumn{8}{|l|}{ Non-health professionals } \\
\hline$n$ & \multirow{2}{*}{\multicolumn{2}{|c|}{$\begin{array}{c}1115 \\
6 \cdot 5\end{array}$}} & \multirow{2}{*}{\multicolumn{2}{|c|}{$\begin{array}{c}2209 \\
4 \cdot 7\end{array}$}} & \multirow{2}{*}{\multicolumn{2}{|c|}{$\begin{array}{c}1776 \\
6.5\end{array}$}} & \\
\hline MetS incidence (unadjusted) (\%) & & & & & & & \\
\hline Age- and sex-adjusted OR & $1 \cdot 00$ & Ref. & 0.68 & $0.49,0.95$ & $0 \cdot 78$ & $0.56,1.09$ & $0 \cdot 27$ \\
\hline Multivariable-adjusted ${ }^{*}$ OR & $1 \cdot 00$ & Ref. & $0 \cdot 72$ & $0.51,1.00$ & $0 \cdot 84$ & $0 \cdot 60,1 \cdot 19$ & 0.51 \\
\hline Additionally adjustedt OR & $1 \cdot 00$ & Ref. & $0 \cdot 73$ & $0.52,1.03$ & $0 \cdot 91$ & $0 \cdot 64,1 \cdot 29$ & $0 \cdot 82$ \\
\hline \multicolumn{8}{|l|}{ Health professionals } \\
\hline$n$ & \multirow{2}{*}{\multicolumn{2}{|c|}{$\begin{array}{c}1100 \\
6 \cdot 8\end{array}$}} & \multirow{2}{*}{\multicolumn{2}{|c|}{$\begin{array}{c}2185 \\
5 \cdot 1\end{array}$}} & \multirow{2}{*}{\multicolumn{2}{|c|}{$\begin{array}{c}1502 \\
6 \cdot 0\end{array}$}} & \\
\hline MetS incidence (unadjusted) (\%) & & & & & & & \\
\hline Age- and sex-adjusted OR & $1 \cdot 00$ & Ref. & $0 \cdot 76$ & $0.55,1.05$ & $0 \cdot 67$ & $0.48,0.94$ & 0.025 \\
\hline Multivariable-adjusted ${ }^{*}$ OR & $1 \cdot 00$ & Ref. & $0 \cdot 75$ & $0.54,1.04$ & $0 \cdot 65$ & $0.45,0.93$ & 0.021 \\
\hline Additionally adjustedt OR & $1 \cdot 00$ & Ref. & $0 \cdot 72$ & $0.51,1.00$ & 0.65 & $0.45,0.94$ & 0.026 \\
\hline
\end{tabular}

Ref., referent category.

*Adjusted for age, smoking, physical activity, alcohol consumption and total energy intake.

tAlso adjusted for BMI.

lower risk of developing MetS than did those who never or almost never consumed nuts (Table 2). This association was slightly attenuated, but remained statistically significant, after multivariate adjustment for potential confounding factors (fully adjusted OR $=0.73$, 95\% CI $0 \cdot 54,0 \cdot 99)$. However, there was no significant linear trend $(P=0 \cdot 23)$ and the estimates suggested an L-shaped dose-response pattern. We additionally adjusted for BMI, because it could be an intermediate variable linking nuts and MetS and similar results were obtained (Table 2).

The inverse association was stronger in women (ageadjusted $\mathrm{OR}=0 \cdot 29,95 \%$ CI $0 \cdot 15,0.56 ; P$ for trend $<0 \cdot 01)$, but it became non-significant among men (Table 2). The $P$ value for interaction (sex $\times$ nuts) was statistically significant $(P=0.0027)$ suggesting that the association differed statistically by sex. When we split the sample according to heath professional status, among health professionals, the fully adjusted odds ratio for nut consumption ( $\geq 1$ serving/week $v$. never or almost never) was 0.65 (95\% CI $0.45,0.94)$ whereas for non-health professionals it was 0.91 (95\% CI 0.64, 1.29). However, there was no evidence of statistical interaction $(P=0 \cdot 43$, $\mathrm{df}=1)$. The results were also non-significant $(P=0 \cdot 60)$ when we used two dummy variables $(\mathrm{df}=2)$ for nut consumption in the interaction product-term. These results are shown in Table 3.

Table 4 shows the multivariable-adjusted odds ratios across categories of nut consumption using as outcome each separate component of the MetS. With the exception of fasting glucose among men, all point estimates of odds ratios for the upper $v$. the lower category of nut consumption suggested inverse associations. However, they were statistically significant only for waist circumference and fasting glucose among women. Table 5 shows the association of nut consumption with each metabolic syndrome component for the sample split according to heath professional status. No significant associations were found. However, among health professionals there was a suggestion of an inverse association for some criteria (high waist circumference and low HDL-cholesterol) although even these results only approached statistical significance and the $95 \%$ confidence interval included the null value.

\section{Discussion}

In this prospective cohort study in a Mediterranean population of relatively young university graduates, nut consumption was inversely associated with the long-term risk of developing MetS. However, we did not find any association among men and the inverse linear trend was significant only among women.

We observed 567 new cases of MetS among 9887 participants, representing an incidence of about $5 \cdot 7 \%$. This incidence of MetS is lower than the incidence reported for the general Spanish population ${ }^{(16)}$, as is to be expected in a cohort of relatively young, slim and physically active graduates with a high educational level. Contrary to a widely held belief, it is important to highlight that nut consumption, when it replaces other snacks, has repeatedly been shown to be associated with lower likelihood of weight gain ${ }^{(10)}$. The inverse association between nut consumption and weight gain found on a previous prospective assessment conducted within the SUN Project ${ }^{(10)}$ was thereafter replicated in the female cohort of the Nurses' Health Study-II ${ }^{(28)}$. Our current results go beyond weight gain to expand this protection also against the development of MetS.

Our study has important strengths such as its large size, the long follow-up period, the previously published studies assessing the validity of our methods and the 
Seguimiento Universidad de Navarra, University of Navarra Follow-up), Navarra, Spain, 1999-2011

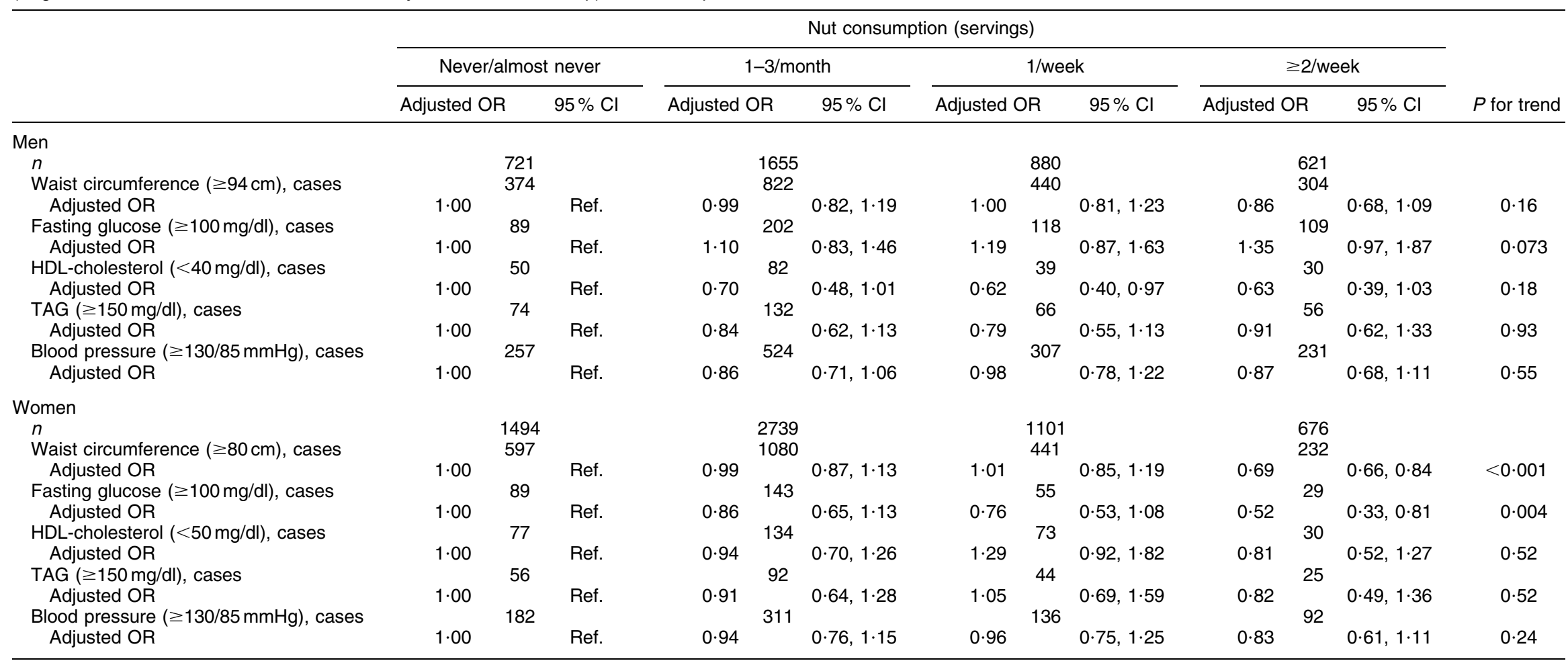

Ref., referent category.

*Adjusted for age, BMI, smoking, physical activity, alcohol intake and total energy intake. 
Table 5 Multivariable-adjusted ${ }^{*}$ odds ratios for each metabolic syndrome component (after 6-year follow-up) according to baseline nut consumption, separating by health professional status. The SUN Project (Seguimiento Universidad de Navarra, University of Navarra Follow-up), Navarra, Spain, 1999-2011

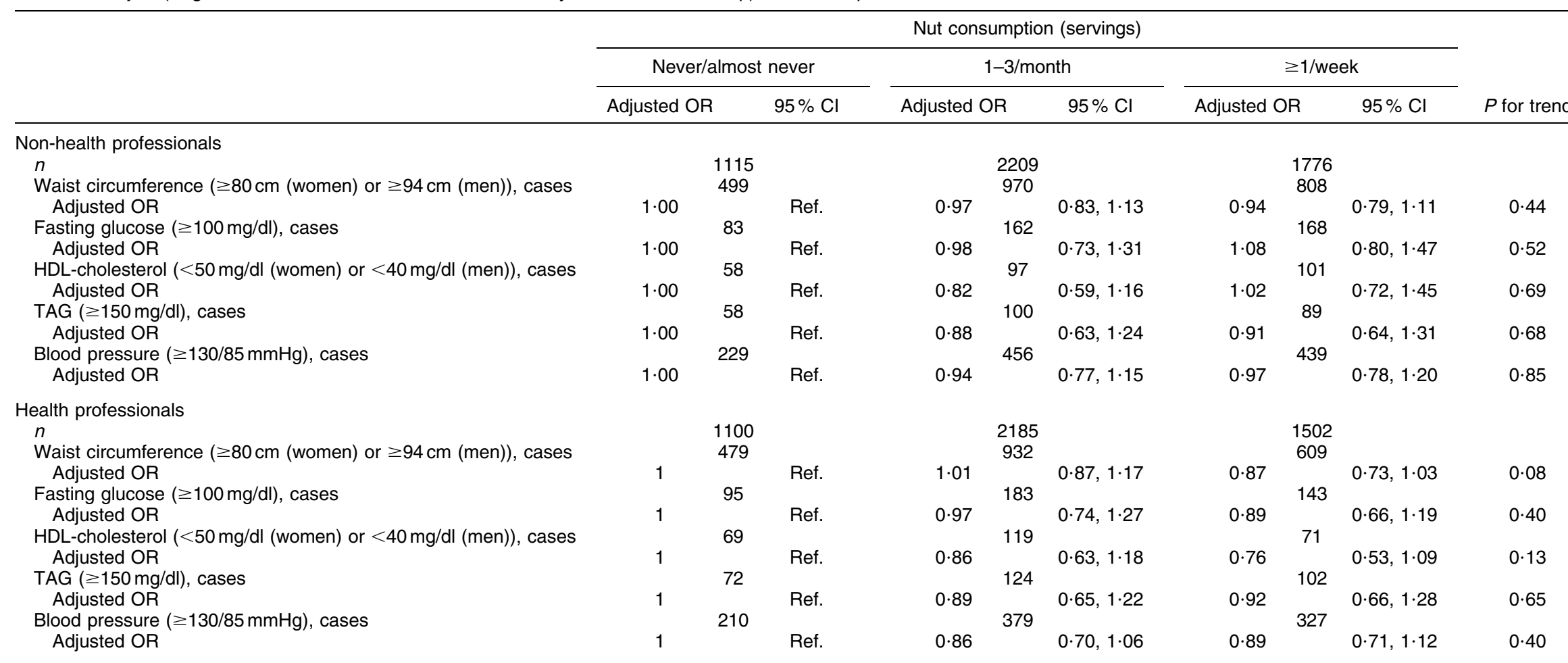

Ref., referent category.

*Adjusted for sex, age, BMI, smoking, physical activity, alcohol intake and total energy intake. 
quality of the self-reported data given by our highly educated volunteers. However, the absolute incidence rates of MetS were low in our cohort and further studies should be done to confirm these findings.

The principal result of our study is that nut consumption was inversely associated with the risk of MetS among women. Although no mechanistic explanation for a differential effect of nuts in women exists, a higher body fat in women and the effect of nuts in reducing weight gain may provide a tentative explanation. It is possible that a poorer dietary assessment among men might have led to a higher measurement error among them. In fact, in the repeatability study of our $\mathrm{FFQ}^{(29)}$ the correlation coefficient for nut consumption was 0.76 among women, but only 0.37 among men. Although FFQ are the most practical and feasible approach to evaluate food habits in large epidemiological studies, it is widely acknowledged that FFQ are prone to measurement errors, and we acknowledge this limitation. In addition, we acknowledge that the identification of MetS is highly dependent on the measurements of lipids, glucose and blood pressure. As we used self-reported data for these parameters, in spite of the validation studies, this is another potential source of misclassification that might have hindered our ability to fully capture the actual association between nut consumption and the incidence of MetS.

We split the sample according to health professional status, although there was no evidence of statistical interaction $(P=0 \cdot 43)$. The reasons for fully presenting an interaction with $P=0.43$ are that the potential for nondifferential misclassification bias is likely to be greater among non-health professionals than among health professionals. In fact, the stronger magnitude of the observed association among health professionals suggests - as expected according to a hypothesis brought up by the blind reviewer - that health professionals might be more knowledgeable about the MetS components and more likely to correctly classify themselves. Thus, our decision to split the sample according to health professional status was prompted by logical reasons and not merely by statistical criteria.

The fact that a significant inverse association was present only among health professionals but not among nonhealth professionals suggests that misclassification of the outcome might partly explain some of our null findings. It seems likely that health professionals might exhibit a better ability to correctly classify themselves, thus reducing the potential for measurement error in epidemiological studies. For this reason, our results suggest that cohorts fully composed of health professional volunteers are an ideal option in epidemiological research. These results are also interesting for public health purposes because large cohorts fully composed of health professionals (the Nurses' Health Study I and II, the Health Professionals Follow-up study and similar cohorts) have in fact provided much of the current mainstream knowledge on the relationships between nutritional exposures and disease occurrence. Our current results, indirectly, support the validity of the knowledge obtained from such cohorts because they suggest that health professionals can overcome even other highly educated individuals in the accuracy of their self-reported information on nutritional and health status variables.

A large randomized trial allocating participants to consume controlled amounts of nuts could circumvent the problem of misclassification because of measurement errors and thus obtain estimates with even better validity. Such a trial is available because the results of 1-year intervention in a subset of high-risk elderly participants in the PREDIMED trial have been published ${ }^{(13)}$. Our longer follow-up and the low absolute risk observed in our participants (essentially healthy individuals) expand those results and add novelty to our findings.

Different mechanisms could explain a protective effect of nuts intake on MetS. Nuts are rich in unsaturated fatty acids, antioxidants and phytosterols ${ }^{(30)}$. Nuts are nutritious foods that provide additional non-lipid nutrients such as fibre, arginine (the precursor of the vasodilator nitrous oxide) and minerals such as $\mathrm{K}, \mathrm{Ca}$ and $\mathrm{Mg}$. Also walnuts are very rich in $\alpha$-linolenic acid, the vegetable $n$-3 fatty acid. These nutrients have beneficial effects on insulin resistance, blood pressure and dyslipidaemia and also can induce reductions in some inflammatory markers ${ }^{(31)}$. All of these mechanisms can account for a protective effect against the MetS.

\section{Conclusions}

In this prospective cohort study of a Mediterranean population composed of university graduates, higher nut consumption was associated with a lower risk of MetS after 6 years of follow-up. The public health implications of our findings, in the context of previous findings, is that important potential benefits for health promotion and for the population prevention of MetS can be obtained by adding tree nuts to the usual diet.

\section{Acknowledgements}

Source of funding: The SUN Study has received funding from the Spanish Government (grants PI01/0619, PI030678, PI040233, PI042241, PI050976, PI070240, PI070312, PI081943, PI080819, PI1002658, PI1002293, RD06/0045, 2010/087 and G03/140), the Navarra Regional Government (grants 36/2001, 43/2002, 41/2005, 36/2008 and 45/2011) and the University of Navarra. Conflicts of interest: The authors declare that they have no competing interests. Authors' contributions: A.F.-M.: design, main author, data collection, fieldwork and writing of the manuscript. M.B.-R.: design, fieldwork, data collection and funding. J.J.B.: data analysis, interpretation and funding. 
M.T.B. and L.M.-G.: data collection and writing. C.d.1.F.-A.: fieldwork and data collection. M.A.M.-G.: project leader, design, fieldwork, data collection, funding, statistical analyses and writing the first draft of the manuscript. All authors contributed to the editing of the manuscript with substantial intellectual and critical contents and they also read and approved the final version of the manuscript.

\section{References}

1. Martínez-González MA \& Sánchez-Villegas A (2004) The emerging role of Mediterranean diets in cardiovascular epidemiology: monounsaturated fats, olive oil, red wine or the whole pattern? Eur J Epidemiol 19, 9-13.

2. Trichopoulou A, Costacou T, Bamia C et al. (2003) Adherence to a Mediterranean diet and survival in a Greek population. N Engl J Med 348, 2599-2608.

3. Kastorini CM, Milionis HJ, Esposito K et al. (2011) The effect of Mediterranean diet on metabolic syndrome and its components: a meta-analysis of 50 studies and 534,906 individuals. J Am Coll Cardiol 57, 1299-1313.

4. Krauss RM, Eckel RH, Howard B et al. (2000) AHA Dietary Guidelines: revision 2000: a statement for healthcare professionals from the Nutrition Committee of the American Heart Association. Circulation 102, 2284-2299.

5. Sabaté J, Oda K \& Ros E (2010) Nut consumption and blood lipid levels: a pooled analysis of 25 intervention trials. Arch Intern Med 170, 821-827.

6. Albert CM, Gaziano JM, Willett WC et al. (2002) Nut consumption and decreased risk of sudden cardiac death in the Physicians' Health Study. Arch Intern Med 162, 1382-1387.

7. Sabaté J \& Ang Y (2009) Nuts and health outcomes: new epidemiologic evidence. Am J Clin Nutr 89, issue 5, 1643S-1648S

8. Jiang R, Manson JE, Stampfer MJ et al. (2002) Nut and peanut butter consumption and risk of type 2 diabetes in women. JAMA 288, 2554-2560.

9. Martínez-González MA \& Bes-Rastrollo M (2011) Nut consumption, weight gain and obesity: epidemiological evidence. Nutr Metab Cardiovasc Dis 21, Suppl. 1, S40-S45.

10. Jenkins DJ, Kendall CW, Banach MS et al. (2011) Nuts as a replacement for carbohydrates in the diabetic diet. Diabetes Care 34, 1706-1711.

11. Gami AS, Witt BJ, Howard DE et al. (2007) Metabolic syndrome and risk of incident cardiovascular events and death: a systematic review and meta-analysis of longitudinal studies. J Am Coll Cardiol 49, 403-414.

12. Casas-Agustench P, Bulló M, Ros E et al. (2011) Crosssectional association of nut intake with adiposity in a Mediterranean population. Nutr Metab Cardiovasc Dis 21, $518-525$.

13. Salas-Salvadó J, Fernández-Ballart J, Ros E et al. (2008) Effect of a Mediterranean diet supplemented with nuts on metabolic syndrome status: one-year results of the PREDIMED randomized trial. Arch Intern Med 168, 2449-2458.

14. Seguí-Gómez M, de la Fuente C, Vázquez Z et al. (2006) Cohort profile: the 'Seguimiento Universidad de Navarra' (SUN) study. Int J Epidemiol 35, 1417-1422.

15. Martínez-González MA (2006) The SUN cohort study (Seguimiento University of Navarra). Public Health Nutr 9, $127-131$.
16. Martínez-González MA, Sánchez-Villegas A, de Irala J et al. (2002) Mediterranean diet and stroke: objectives and design of the SUN project. Nutr Neurosci 5, 65-73.

17. Tortosa A, Seguí-Gómez M, de la Fuente C et al. (2008) Diferencias en estilos de vida y calidad de la información autorreferida según nivel de estudios: el proyecto SUN. Rev Med Univ Navarra 52, 15-19.

18. Bes-Rastrollo M, Pérez Valdivieso JR, Sánchez-Villegas A et al. (2005) Validación del peso e índice de masa corporal auto-declarados de los participantes de una cohorte de graduados universitarios. Rev Esp Obes 3, 183-189.

19. Martínez-González MA, López-Fontana C, Varo JJ et al. (2005) Validation of the Spanish version of the physical activity questionnaire used in the Nurses' Health Study and Health Professionals' Follow-up study. Public Health Nutr 8, 920-927.

20. Alonso A, Beunza JJ, Delgado-Rodríguez M et al. (2005) Validation of self reported diagnosis of hypertension in a cohort of university graduates in Spain. BMC Public Health 5, 94 .

21. Fernández-Montero A, Beunza JJ, Bes-Rastrollo $\mathrm{M}$ et al. (2011) Validación de los componentes del síndrome metabólico autodeclarados en un estudio de cohortes. Gac Sanit 25, 303-307.

22. Barrio-Lopez MT, Bes-Rastrollo M, Beunza JJ et al. (2011) Validation of metabolic syndrome using medical records in the SUN cohort. BMC Public Health 11, 867.

23. Martín-Moreno JM, Boyle P, Gorgojo L et al. (1993) Development and validation of a food frequency questionnaire in Spain. Int J Epidemiol 22, 512-519.

24. Fernández-Ballart JD, Piñol JL, Zazpe I et al. (2010) Relative validity of a semi-quantitative food-frequency questionnaire in an elderly Mediterranean population of Spain. BrJ Nutr 103, 1808-1816.

25. Mataix J (2003) Tabla de Composición de Alimentos (Food Composition Tables), 4th ed. Granada: Universidad de Granada.

26. Moreiras O (2005) Tablas de Composición de Alimentos (Food Composition Tables), 9th ed. Madrid: Ediciones Pirámide.

27. Alberti KG, Eckel RH, Grundy SM et al. (2009) International Diabetes Federation Task Force on Epidemiology and Prevention; National Heart, Lung, and Blood Institute; American Heart Association; World Heart Federation; International Atherosclerosis Society; International Association for the Study of Obesity. Harmonizing the metabolic syndrome: a joint interim statement of the International Diabetes Federation Task Force on Epidemiology and Prevention; National Heart, Lung, and Blood Institute; American Heart Association; World Heart Federation; International Atherosclerosis Society; and International Association for the Study of Obesity. Circulation 120, 1640-1645.

28. Bes-Rastrollo M, Wedick NM, Martínez-González MA et al. (2009) Prospective study of nut consumption, long-term weight change, and obesity risk in women. Am J Clin Nutr 89, 1913-1919.

29. De la Fuente-Arrillaga C, Ruiz ZV, Bes-Rastrollo M et al. (2010) Reproducibility of an FFQ validated in Spain. Public Health Nutr 13, 1364-1372.

30. Estruch R, Martínez-González MA, Corella D et al. (2006) Effects of a Mediterranean style diet on cardiovascular risk factors: a randomized trial. Ann Intern Med 145, 1-11.

31. Fitó M, Guxens M, Corella D et al. (2007) Effect of a traditional Mediterranean diet on lipoprotein oxidation: a randomized controlled trial. Arch Intern Med 167, $1195-1203$. 